\section{UJMM

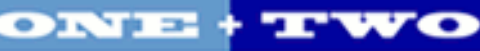

Volume 3 | 2010 Fall

\section{Undergraduate Journal of Mathematical}

Modeling: One + Two

Article 24

2010

\title{
Escape Velocity
}

Nikola Vlacic

University of South Florida

Advisors:

Masahiko Saito, Mathematics and Statistics

Scott Campbell, Chemical \& Biomedical Engineering

Carlos Smith, Chemical \& Biomedical Engineering

Problem Suggested By: Scott Campbell

Follow this and additional works at: https://digitalcommons.usf.edu/ujmm

Part of the Mathematics Commons

UJMM is an open access journal, free to authors and readers, and relies on your support:

Donate Now

\section{Recommended Citation}

Vlacic, Nikola (2010) "Escape Velocity," Undergraduate Journal of Mathematical Modeling: One + Two:

Vol. 3: Iss. 1, Article 12.

DOI: http://dx.doi.org/10.5038/2326-3652.3.1.24

Available at: https://digitalcommons.usf.edu/ujmm/vol3/iss1/24 


\title{
Escape Velocity
}

\begin{abstract}
In this project, we investigated if it is feasible for a single staged rocket with constant thrust to attain escape velocity. We derived an equation for the velocity and position of a single staged rocket that launches vertically. From this equation, we determined if an ideal model of a rocket is able to reach escape velocity.
\end{abstract}

Keywords

Escape Velocity, Single Staged Rocket, Kinetic Energy

Creative Commons License

(c) (i) ()

This work is licensed under a Creative Commons Attribution-Noncommercial-Share Alike 4.0 License.

\section{Erratum}

This article was previously called Article 24. 


\section{TABLE OF CONTENTS}

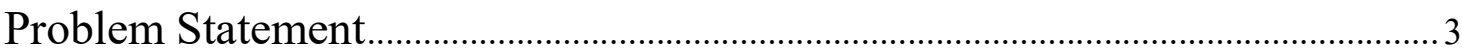

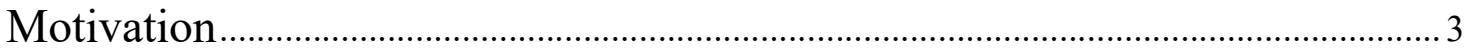

Mathematical Description and Solution Approach ................................................. 3

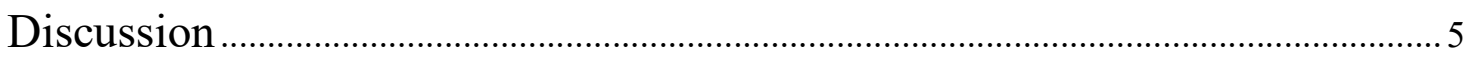

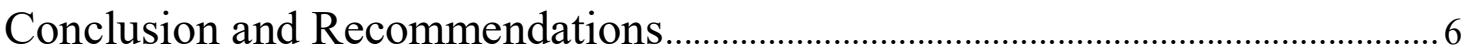

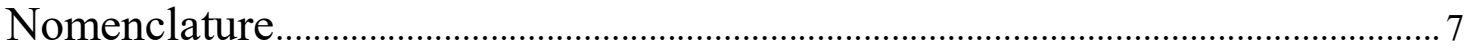

References 


\section{PROBLEM STATEMENT}

The objective of this project is to determine the velocity needed for a single staged rocket to leave Earth's gravity and how much fuel would be required.

We ignore the effects of the Earth's rotation and assume that the rocket only travels vertically in order to simplify the calculations. Additionally, we ignore the drag forces since rockets tend to be very massive and they quickly ascend to heights where the air resistance becomes negligible. Therefore, the only forces which we shall take into account are thrust and gravity. Throughout this project we shall assume that the rocket is a single staged rocket. The Saturn V rocket and the Space Shuttle are multi-staged rockets that discard their fuel tanks and rocket engines once their fuel is consumed.

\section{Motivation}

Understanding the requirements for achieving escape velocity can give engineers and scientists a starting point for more complex problems. For instance, it is necessary for a rocket to attain escape velocity in order for the rocket to reach the moon or for the rocket to reach the depths of the solar system.

\section{MATHEMATICAL DESCRIPTION AND SOLUTION APPROACH}

In this problem, we shall let $t$ denote the time after the rocket launches. We also let $y(t)$ denote the height of the rocket above earth's surface at time $t$. Recall that the only forces that we consider acting on the rocket are thrust and gravity. Since acceleration is the second derivative of position, we have 


$$
F_{t}-F_{g}=F=m a=m(t) \frac{d^{2} y(t)}{d t^{2}}
$$

where $F_{t}$ and $F_{g}$ are the forces of thrust and gravity and $m(t)$ is the mass of the rocket at time $t$. The law of universal gravitation states that

$$
F_{g}=G_{c} \frac{m_{e} m(t)}{(r+y(t))^{2}}
$$

where $G_{c}$ is the universal gravitational constant, $m_{e}$ is the mass of the Earth, $m(t)$ is the mass of the rocket, $t$ is the time after launch, and $r$ is the radius of the Earth. We also have

$$
m(t)=R+F-C t
$$

where $R$ is the mass of the rocket without fuel, $F$ is the mass of the initial fuel load, and $C$ is the rate of fuel consumption. We shall assume that the fuel burns at a constant rate and the thrust is constant. By substituting the functions $m(t)$ and $F_{g}$ we get

$$
F_{t}-G_{c} \frac{m_{e}(R+F-C t)}{(r+y(t))^{2}}=(R+F-C t) \frac{d^{2} y(t)}{d t^{2}}
$$

therefore

$$
\frac{d^{2} y}{d t^{2}}=\frac{F_{t}}{(R+F-C t)}-G_{C} \frac{m_{e}}{(r+y(t))^{2}} .
$$

For an object to have enough speed to leave the gravitational pull of the Earth, the object's kinetic energy must be great enough to lift the object to outer space. The energy required to lift the rocket from height $y$ into space is the integral

$$
\int_{y}^{\infty} G_{c} \frac{m_{e} m}{(r+z)^{2}} d z=G_{c} m_{e} m \frac{1}{r+y} .
$$

Therefore, in order to have more kinetic energy than potential energy, we must have

$$
\frac{1}{2} m\left(\frac{d y}{d t}\right)^{2} \geq G_{c} m_{e} m \frac{1}{r+y}
$$


In other words, if $t_{f}$ is the time that the rocket runs out of fuel and $V_{f}$ is the velocity when the rocket runs out of fuel, then in order to have enough kinetic energy to escape Earth's gravitational field we must have

$$
V_{f} \geq \sqrt{\frac{2 G_{c} m_{e}}{r+y\left(t_{f}\right)}}
$$

\section{DISCUSSION}

We shall now compute whether it is reasonable for a single staged rocket to achieve escape velocity. The velocity $4,500 \mathrm{~m} / \mathrm{s}$ is near the theoretical maximum exhaust velocity for chemical rockets that burn fuel, and it is nearly impossible to have a rocket that is $90 \%$ fuel (Turner. 16-17). Furthermore, since chemical rockets have very high thrust to weight ratios compared to all other propulsion systems, chemical rockets are the only feasible rocket systems capable of reaching escape velocity (Sutton. 30). We shall therefore assume that we have a rocket where the mass of the rocket with fuel is $4 \times 10^{6} \mathrm{~kg}$, and the mass of the rocket without fuel is $5 \times 10^{5} \mathrm{~kg}$. Furthermore, assume that the average exhaust velocity is $4,000 \mathrm{~m} / \mathrm{s}$ and the rocket burns $2 \times 10^{4} \mathrm{~kg}$ of fuel per second. With these optimal specifications, the rocket produces $8 \times 10^{7} \mathrm{~N}$ of thrust, and the engine burns for $175 \mathrm{~s}$. By solving the differential equation (2) numerically, we conclude that the rocket achieves a velocity of $6,649.18 \mathrm{~m} / \mathrm{s}$ at $343 \mathrm{~km}$ above the earth's surface after $175 \mathrm{~s}$. On the other hand, the escape velocity at $343 \mathrm{~km}$ above earth's surface is $1,0896 \mathrm{~m} / \mathrm{s}$. This rocket did not reach escape velocity. Furthermore, the air resistance further hinders the rocket's ability to reach escape velocity. In addition to the problem of not being able to reach escape velocity, there are other problems with this rocket model. In this model, the rocket exerts 16 times the force of gravity after $175 s$ while at launch 
the rocket only exerts two times the force of gravity. This acceleration will produce a great amount of stress on the rocket and will not be bearable for any passengers inside the rocket.

\section{CONCLUSION AND RECOMMENDATIONS}

We conclude that it is not reasonable for a single staged rocket of constant thrust to escape Earth's gravitational field when launched vertically. In order for a chemically based rocket to reach escape velocity, it is necessary for the rocket to discard excess fuel tanks and engines. 


\section{NOMENCLATURE}

\begin{tabular}{|clc|}
\hline Symbol & Description & Units \\
\hline$t$ & Time after launch & Seconds $(s)$ \\
\hline$y(t)$ & Height of rocket & Meters $(\mathrm{m})$ \\
\hline$F_{t}$ & Force of thrust & Newtons $(\mathrm{N})$ \\
\hline$F_{g}$ & Force of gravity & $\mathrm{N}$ \\
\hline$m(t)$ & Mass of Rocket & Kilograms $(\mathrm{kg})$ \\
\hline$R$ & Mass of rocket without fuel & $\mathrm{kg}$ \\
\hline$F$ & Mass of fuel & $\mathrm{kg} / \mathrm{s}$ \\
\hline$C$ & Rate of fuel consumption & $\mathrm{N}(\mathrm{m} / \mathrm{kg})^{2}$ \\
\hline$G_{c}$ & Universal gravitational constant & $\mathrm{kg}$ \\
\hline$m_{e}$ & Mass of earth & $\mathrm{m}$ \\
\hline$R$ & Radius of earth & $\mathrm{s}$ \\
\hline$t_{f}$ & Length of engine burn & $\mathrm{m} / \mathrm{s}$ \\
\hline$V_{f}$ & Final velocity & \\
\hline
\end{tabular}

\section{REFERENCES}

George P. Sutton. Rocket Propulsion Elements. New York: Wiley-Interscience,1986.

Martin J. L. Turner. Rocket and Spacecraft Propulsion. Chichester, UK:

Praxis Publishing Ltd., 2000. 